\title{
Hydrology and hydraulic properties of a bedded evaporite formation
}

\author{
Richard L. Beauheim and Randall M. Roberts \\ Sandia National Laboratories, Carlsbad, NM 88220, USA
}

\begin{abstract}
The Permian Salado Formation in the Delaware Basin of New Mexico is an extensively studied evaporite deposit because it is the host formation for the Waste Isolation Pilot Plant, a repository for transuranic wastes. Geologic and hydrologic studies of the Salado conducted since the mid1970 's have led to the development of a conceptual model of the hydrogeology of the formation that involves far-field permeability in anhydrite layers and at least some impure halite layers. Pure halite layers and some impure halite layers may not possess an interconnected pore network adequate to provide permeability. Pore pressures are probably very close to lithostatic pressure. In the near field around an excavation, dilation, creep, and shear have created and/or enhanced permeability and decreased pore pressure. Whether flow occurs in the far field under natural gradients or only after some threshold gradient is reached is unknown. If far-field flow does occur, mean pore velocities are probably on the order of a meter per hundreds of thousands to tens of millions of years.
\end{abstract}

Flow dimensions inferred from most hydraulic-test responses are subradial, which is believed to reflect channeling of flow through fracture networks, or portions of fractures, that occupy a diminishing proportion of the radially available space, or through percolation networks that are not "saturated" (fully interconnected). This is probably related to the directional nature of the 


\section{DISCLAIMER}

This report was prepared as an account of work sponsored by an agency of the United States Government. Neither the United States Government nor any agency thereof, nor any of their employees, make any warranty, express or implied, or assumes any legal liability or responsibility for the accuracy, completeness, or usefulness of any information, apparatus, product, or process disclosed, or represents that its use would not infringe privately owned rights. Reference herein to any specific commercial product, process, or service by trade name, trademark, manufacturer, or otherwise does not necessarily constitute or imply its endorsement, recommendation, or favoring by the United States Government or any agency thereof. The views and opinions of authors expressed herein do not necessarily state or reflect those of the United States Government or any agency thereof. 


\section{DISCLAIMER}

Portions of this document may be illegible in electronic image products. Images are produced from the best available original document. 
permeability created or enhanced by excavation effects. Inferred values of permeability cannot be separated from their associated flow dimensions. Therefore, numerical models of flow and transport should include heterogeneity that is structured to provide the same flow dimensions as are observed in hydraulic tests. Modeling of the Salado Formation around the WIPP repository should also include coupling between hydraulic properties and the evolving stress field because hydraulic properties change as the stress field changes.

\section{Introduction}

RECEIVED NOV 302000

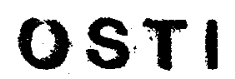

The hydrology of evaporite deposits is generally little studied and is poorly understood. The Permian Salado Formation in the Delaware Basin of New Mexico is one of the most extensively studied evaporite deposits in the world because it is the host formation for the Waste Isolation Pilot Plant (WIPP), a repository for transuranic wastes generated by the United States' defense programs. As part of WIPP site characterization, geologic and hydrologic studies of the Salado have been conducted since the mid-1970's. In the following paper, we describe our conceptual model for Salado hydrology and discuss the data that have been used to develop that model. We consider both the hydrology of the Salado in the far field, unaffected by the presence of the WIPP excavations, and in the near field or disturbed rock zone (DRZ) around the repository. We also discuss aspects of the conceptual model that are important to include in numerical models of Salado hydrology. 


\section{Salado Geology}

The Salado Formation is approximately $600 \mathrm{~m}$ thick at the WIPP site and lies approximately 260 to $860 \mathrm{~m}$ below ground surface. It is composed largely of bedded halite, with minor amounts of interspersed clay and polyhalite. The Salado also contains interbeds of anhydrite, polyhalite, clay, and siltstone. Many of these interbeds are traceable over most of the Delaware Basin. Jones et al. (1960) designated 45 of the continuous anhydrite and/or polyhalite interbeds as "Marker Beds", and numbered these Marker Beds (MB) from 100 to 144, increasing downward. The WIPP facility horizon (the stratigraphic location of the underground excavations) lies between MB138 and MB139, approximately $655 \mathrm{~m}$ below ground surface.

A typical stratigraphic section of a 58-m interval of the Salado, centered approximately at the stratigraphic midpoint of the WIPP excavations, is shown in Figure 1. Sixteen "map units" numbered 0 to 15 and 39 other identifiable units have been described by Deal et al. (1989) and Roberts et al. (1999). The majority of the units are composed primarily of halite, and are differentiated principally on the basis of differing clay and polyhalite contents, which rarely exceed 5\%. The halite units lacking integer map-unit designations are identified by $\mathrm{H}$ (pure halite), $\mathrm{AH}$ (argillaceous halite), or $\mathrm{PH}$ (polyhalitic halite) prefixes, followed by a number or letter ("m" for "minus")-number combination representing that unit's position with respect to the base of the sequence, which was arbitrarily defined as the halite unit immediately underlying anhydrite "c" and clay B. For example, AH-4 is the fourth argillaceous halite unit above the base of the sequence and $\mathrm{H}-\mathrm{m} 1$ is the first halite unit below the base of the sequence. The remainder of the units are sulfatic interbeds, such as MB138 and MB139, and clay seams. The interbeds are composed primarily of anhydrite, with lesser amounts of polyhalite and halite. 


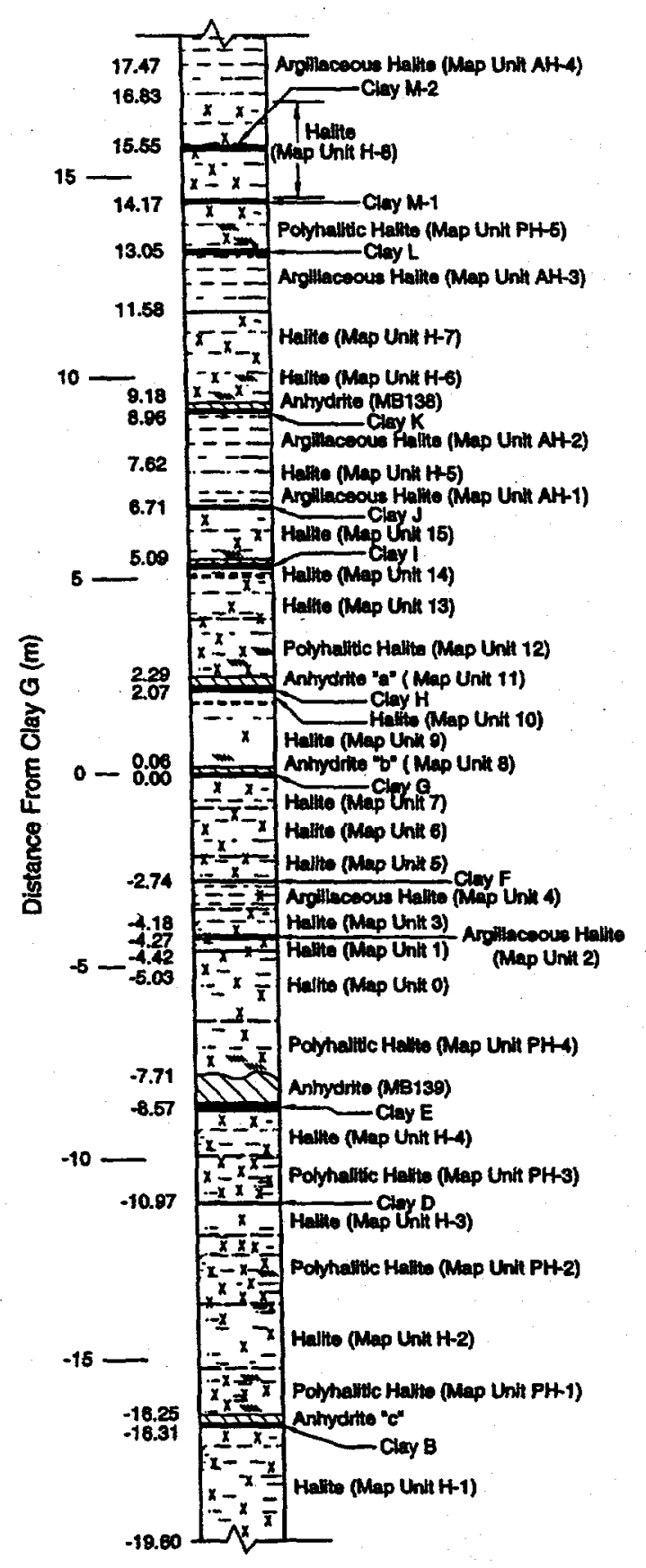

Adapted from Westinghouse (1989) and Ded of al. (1889)
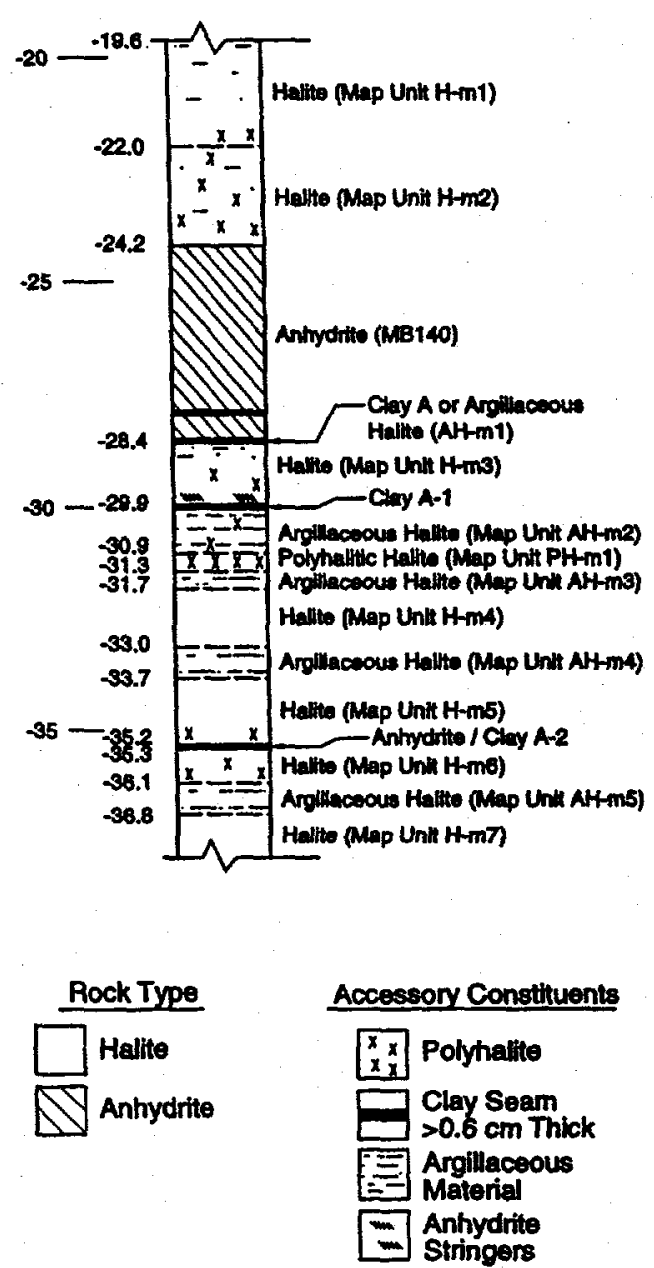

Lithologic Contacts

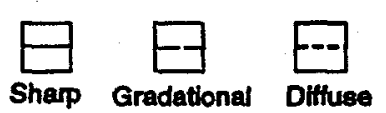

Notes:

1. Distances in meters are meapured trom the base of antyctilte "b" (Cloy G) and ane everaged from representethe corchole loge, shaft and teet-room mapping. Actual dietance and unit thickneeses: may very locally from those shown.

2. Deectiptions of units are besed on corchole dater thaft mapping end viaual thapection of exposure. in underground dithe and rooms.

Thancase-1

Figure 1. Detailed stratigraphy near the WIPP underground facility. 
Thinner sulfatic interbeds and a number of the more continuous clay seams have also been given letter designations (e.g., anhydrite "a", clay B) to facilitate consistent referencing. These units are shown in Figure 1. The stratigraphic positions of the WIPP excavations with respect to the designated map units are shown in Figure 2.

\section{Conceptual Models}

\subsection{Far-Field Salado Hydrology}

Our conceptual model for far-field Salado hydrology is as follows. Porosity of both halite and anhydrite is low, on the order of 0.01 . All interconnected porosity is filled with brine containing dissolved gases, principally nitrogen. Because halite is a creeping medium, pore pressures are expected to be lithostatic, or very close thereto. Different layers have different permeabilities; anhydrites and clay-rich layers have the highest permeabilities and pure halites have the lowest permeabilities. Some halite beds may have no permeability because of inadequate connection of the pores. Anhydrite permeability derives from naturally occurring bedding-plane fractures (Borns, 1985). The pure halite layers with extremely low to nonexistent permeabilities impede vertical flow of brine, so most flow through the Salado is horizontal, parallel to bedding. Within an individual bed, flow may be channelized into relatively high-permeability pathways created either by natural heterogeneity or by syndepositional dissolution troughs filled with pure halite (Powers and Hassinger, 1985) cutting across the bed that limit flow in certain directions. Gasthreshold (air-entry) pressures of the evaporites are high, probably exceeding the hydraulicfracturing pressures, because of the very low permeabilities. 


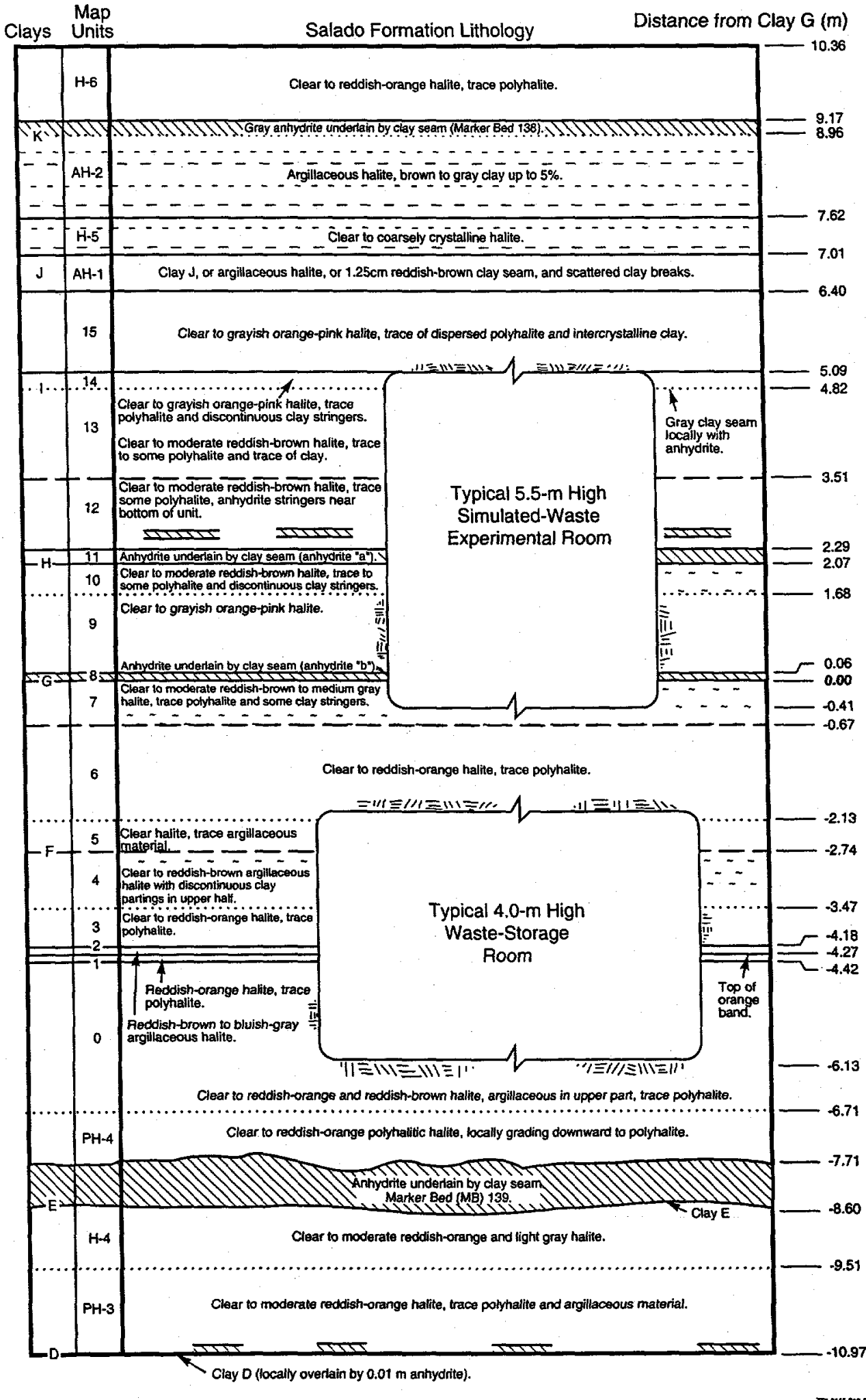

Figure 2. Schematic of typical WIPP underground rooms showing stratigraphic positions. 
We assume that flow is driven by pressure gradients and follows Darcy's law, as in most porous media. However, as pointed out by Neuzil (1986), Darcy flow has never actually been demonstrated in low-permeability formations such as the Salado under natural low gradients. Other researchers (e.g., Swartzendruber, 1962; Pascal, 1981; Remson and Gorelick, 1982) have suggested that low-permeability media may have threshold gradients below which no flow can occur, perhaps related to capillarity or surface-tension effects in very small pores. Thus, Darcy flow in the far field is unproven. To whatever extent regional flow is occurring under the naturally occurring gradients, it is expected to be toward areas of lower overburden pressure. Flow is expected to be unmeasurably slow, however. Given a halite permeability that we think might be representative of far-field conditions of $10^{-22} \mathrm{~m}^{2}$ (hydraulic conductivity of $\sim 10^{-15} \mathrm{~m} / \mathrm{s}$ ), a hydraulic gradient of 0.01 , and a porosity of 0.01 , brine would take approximately 30 million years to flow one meter. In anhydrite, where the permeability might be one hundred times higher, brine would still take over 300,000 years to flow one meter.

\subsection{Excavation Effects on Near-Field Hydrology}

When the WIPP repository was mined, the far-field hydrologic system was altered locally by a variety of mechanical and coupled hydraulic and mechanical processes. These "excavation effects" are discussed below.

When an excavation is first mined, inelastic dilation (volume expansion) of the surrounding rock mass occurs as the rock expands into the newly created void volume. This dilation affects both the solid volume and pore volume of the rock. In part, the dilation is manifested as grainboundary separation and readjustment. As the pores dilate, the fluid pressure in the pores 
decreases. If the pores dilate more than the brine can expand, partially saturated conditions may result. Gas may come out of solution as the pore pressure decreases, resulting in two-phase conditions.

Peach (1991) discussed the effects of dilation on halite permeability in terms of percolation theory. Under undisturbed conditions, the low porosity of halite may be too poorly connected to reach the percolation threshold-the minimum pore connectivity at which flow can occur. Without a throughgoing, interconnected pore network on the scale of measurement, a medium will show zero permeability. Given small amounts of dilation $(\geq 0.05$ volume \%), however, Peach (1991) found that sufficient grain-boundary microfracturing occurs to create an interconnected pore network beyond the percolation threshold. From the percolation threshold, permeability increases rapidly with increasing dilation until the pore network is "saturated" (fully interconnected), which occurs at some dilation less than $1 \%$. Beyond the saturation point, increased dilation has little effect on permeability. Thus, dilation around an excavation can cause halite to shift from a condition in which permeability is effectively nonexistent to a condition with measurable permeability. The dilatancy of halite is enhanced by the presence of impurities (e.g., anhydrite, clay), so impure halite will dilate, and thereby increase in permeability, to a greater distance from an excavation than pure halite. Note that we do not apply this percolation model to anhydrite, in which flow occurs through naturally occurring fractures.

In addition to dilation, stress changes occur around the mined opening. The vertical load that had been borne by the removed rock is transferred to the pillars adjacent to the room, creating a 
compressive vertical stress concentration in the ribs of the excavation. This compressive stress may act to heal any grain-boundary separations that have occurred in halite, particularly if the pore pressure has decreased. At the same time, the horizontal stress at the excavation ribs is reduced to zero. In halite, the resulting deviatoric stress causes the rock to creep toward the excavation. Porosity and permeability are continually created as creep occurs. Close to the excavation where the most creep occurs, extensional strain fractures may develop parallel to the excavation surface.

Stresses are concentrated at the corners of an excavation, resulting in shear fracturing. Shear fractures arc around the opening, creating an effective opening with a more mechanically stable elliptical cross section (Borns and Stormont, 1988, 1989). At WIPP, this idealized picture is complicated by the presence of layers with different properties, particularly anhydrite and clay interbeds. The shear fractures that form at the upper corners of WIPP excavations arc upwards toward the nearest anhydrite/clay seam, typically anhydrite "b"/clay G (Figure 2). The anhydrite interbeds are stiffer than the overlying and underlying halite, and tend to separate from the halite along shear planes. With time, all of the rock inside the shear planes becomes decoupled from the surrounding rock mass. This leads to roof falls of all the rock between the back of an excavation and clay G.

The permeability created (or enhanced) by excavation effects is not isotropic. Grain-boundary microcracking occurs predominantly in the direction of maximum compressive stress, while extension fracturing occurs parallel to an excavation face (perpendicular to the minimum principal stress). In addition, the vertical compressive stress in the ribs of excavations will tend 
to heal horizontal microfractures. Thus, permeability around excavations has strong directional dependency.

\section{Hydraulic Testing}

Pressure-pulse, constant-pressure flow, and pressure-recovery tests were performed between 1988 and 1995 in boreholes drilled from within the WIPP excavations to evaluate the hydraulic properties controlling brine flow in the vicinity of the repository. Test locations are shown in Figure 3. Interpretations of the tests using the model GTFM (Pickens et al., 1987) were reported by Beauheim et al. (1991 and 1993), Domski et al. (1996), and Roberts et al. (1999).

The tests were conducted in boreholes drilled to a variety of distances and in different orientations with respect to the underground excavations. After drilling, the holes were filled with native Salado brine and test tools with multiple packers were installed. The bottom-hole interval was the primary test zone in each hole, while the intervals between packers served as either guard zones (to guard against leaks) or secondary test zones. Hydraulic testing commenced after an initial pressure-buildup period. Two primary groups of tests were performed. One set of tests, involving fifteen boreholes, was performed to determine how hydraulic properties were affected by the excavation of a cylindrical opening, Room Q (Figure 3). The other set of tests was performed in 12 boreholes drilled at different locations in the WIPP excavations. These tests provided information about hydraulic properties around existing excavations at the time of testing. 


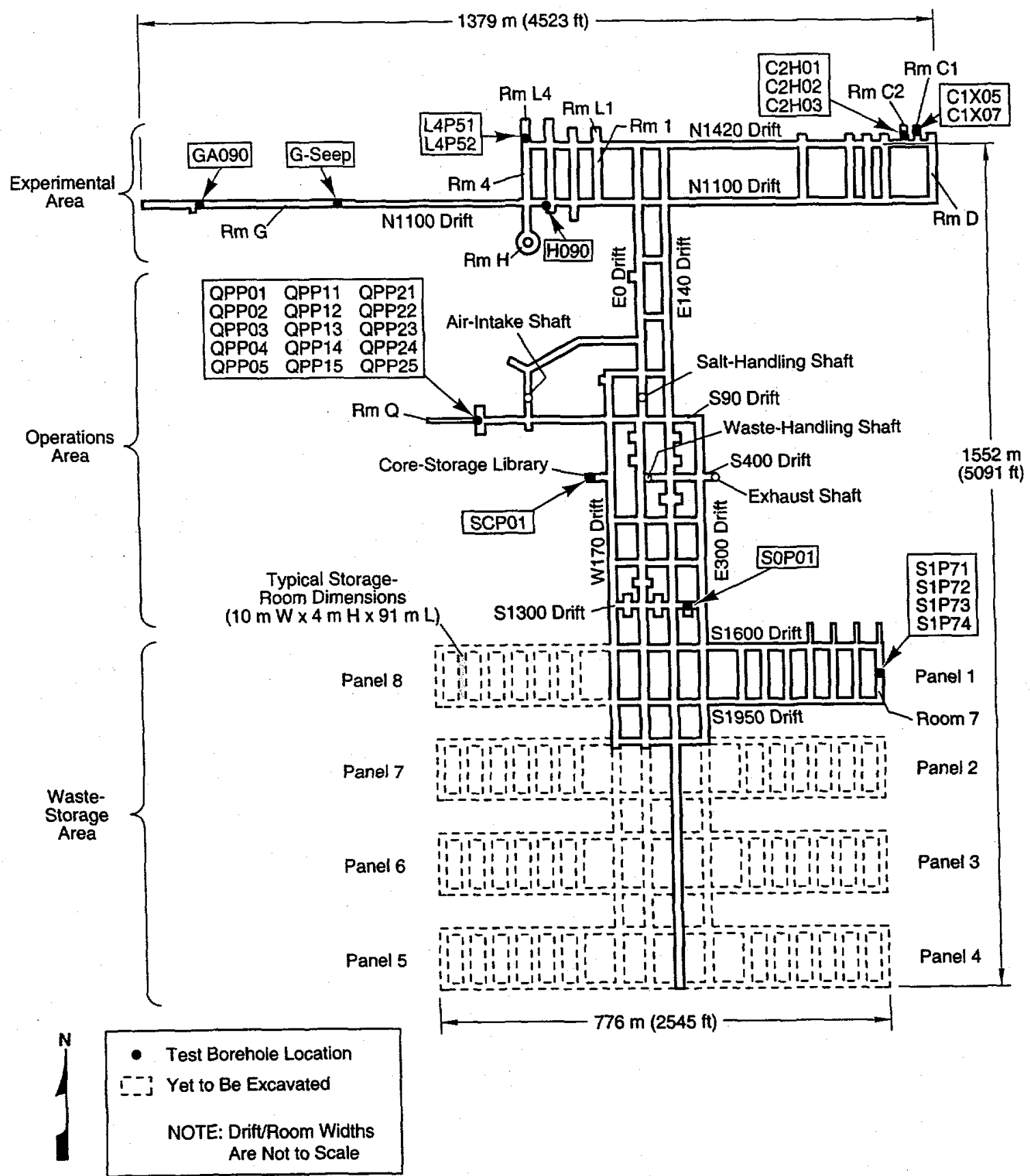

TA1-6330-129-6

Figure 3. Map of the WIPP underground facility showing test locations. 
A third set of tests involving 12 test holes called the Small-Scale Mine-By experiment was performed by Stormont et al. (1991a, b). The purpose of these tests was to determine how the drilling of a $96.5-\mathrm{cm}$-diameter hole would affect hydraulic properties around the hole. Half of these tests were conducted using brine and the other half were conducted using gas.

Before discussing the results of the three testing programs, we will introduce the concept of flow dimensions. Consideration of flow dimensions affects both the estimates of hydraulic properties inferred from hydraulic tests and the conceptualization of how those properties are distributed in space.

\subsection{Flow Dimensions}

Hydraulic-test-interpretation methods have traditionally assumed that flow occurs radially toward or away from test boreholes, and that the flow fills all of the available space. In highly heterogeneous and/or fractured systems, particularly around an excavation where the stress field is changing in both time and space, these assumptions may not be valid. Notable attempts to expand well-test-interpretation methodologies to characterize nonradial flow can be found in Black et al. (1986), Barker (1988), Noy et al. (1988), and Doe (1991), where the concept of a flow dimension $(n)$ is introduced. Barker (1988) discussed flow systems with constant hydraulic conductivity $(K)$ and specific storage $\left(S_{s}\right)$ where the flow dimension of the system was related to the power by which the flow area changed with distance from the source and $n$ described the geometry of the system. The flow area in this formulation is given by: 


$$
\operatorname{Area}(r)=b^{3-n} \frac{2 \pi^{\frac{n}{2}}}{\Gamma\left(\frac{n}{2}\right)} r^{n-1}
$$

$$
\text { where: } \begin{array}{rll}
n & = & \text { flow dimension } \\
b & = & \text { extent of the flow zone, } \mathrm{L} \\
\Gamma & = & \text { gamma function } \\
r & =\quad \text { radial distance from borehole, } \mathrm{L}
\end{array}
$$

The flow dimension $n$ is related to the power-law relationship between flow area and radial distance from the borehole. The flow dimension is defined as the power of variation plus one. For example, the relationship between flow area and distance in a standard radial system is given by:

$$
\operatorname{Area}(r)=2 \pi r b
$$

The flow area is seen to vary linearly with distance $\left(r^{l}\right)$, making the flow dimension, by definition, two. All of the diagnostic methods used to deduce radial flow, i.e., the shapes of various type curves, depend only on the relationship between flow area and distance ( $r$ ). The shapes of the type curves are independent of the constant $2 \pi b$, so they provide no information on the degree to which the flow system fills the available space.

Roberts et al. (1999) showed that the dimensionality of flow can be deduced for any type of test from diagnostic plots of pressure and/or flow-rate changes and their derivatives. They 
interpreted flow as being nonradial in most of the Salado intervals in which hydraulic tests were performed. Of the 16 test responses they considered, they found flow to be subradial in nine cases, superradial in five cases, and radial in only two cases. Subradial $(<2)$ flow dimensions, such as those interpreted from the tests of MB138 in L4P52 and S1P74 and of clay J in S1P74, are consistent with a medium in which fractures or pores are poorly interconnected or a medium in which flow is channeled through those portions of fractures having the largest apertures. In either case, the fractures or pores involved in flow occupy a proportion of the radially available space that diminishes with distance from the test hole. A superradial $(>2)$ flow dimension suggests a system in which fracture/pore connectivity and/or density increase(s) with distance, or in which the space available for flow is expanding in a third dimension (e.g., spherical flow).

These results provide information useful in understanding flow through the Salado. As discussed in detail in Roberts et al. (1999), however, flow dimensions are somewhat problematic in that radial (dimension $=2$ ) flow in a system with distance-varying hydraulic parameters cannot be distinguished from nonradial flow in a system with constant hydraulic parameters (in a singlewell test). In addition, time-varying (or pressure-dependent) properties can be difficult to distinguish from spatially varying properties. To deal with these ambiguities, the concept of variable flow dimensions was broadened to include the nonunique combinations of temporal and spatial variations in flow geometries and hydraulic parameters. The baseline analysis of any test could then be transformed into different, nonunique combinations of geometries and hydraulic parameters as desired. 
All of the excavation effects described above are location-specific and time-dependent and affect flow dimensions around an excavation in a variety of ways. If hydraulic properties in an individual layer change with distance from an excavation, a hydraulic test conducted in that layer will likely show a nonradial flow dimension. Whether the specific flow dimension is greater or less than radial will depend on the specific spatial pattern of variation of hydraulic properties. If a propagating pressure transient encounters a region of decreased permeability, the flow dimension will decrease, while a region of increased permeability will have an opposite effect. Fractures connecting two permeable layers that are otherwise separated will tend to increase the flow dimension. In a percolation network, the flow dimension should increase as the connectivity of the network increases. Thus, we might expect to see an increase in flow dimension in halite that has undergone dilation close to an excavation compared to the same halite at a greater distance from an excavation, unless the new pore connectivity is highly directional.

Flow dimensions that change as the volume of influence of a test expands should be expected. For instance, stress relief directly above or below an excavation may result in a zone of increased fracturing (and/or permeability) within the "footprint" (vertical projection) of the excavation, with less fracturing (lower permeability) under the ribs of the excavation. When a propagating pressure transient reaches some type of discontinuity that restricts flow, such as a zone of decreased permeability or, in the extreme, a no-flow boundary, the flow dimension initially decreases rapidly. Thus, a rapid transition to a sublinear to negative flow dimension is best interpreted as a qualitative indication of a sudden reduction in permeability and/or flow area at some distance from the test hole. With time, the flow dimension will increase to a value 
representing the rate at which the permeability-area product continues to increase as the pressure transient propagates further in other directions (i.e., away from the "boundary"). The flow dimensions from the first and second constant-pressure-withdrawal (CPW) tests of $\mathrm{H}-\mathrm{m} 2$ in L4P51, respectively, illustrate these points. The flow dimension was initially between 1.5 and 1.8 during both tests, reflecting slightly subradial to radial conditions. The flow dimensions then decreased to negative values, reflecting some restriction to flow with distance from the borehole. After a transition period, the flow dimension rose and stabilized at a value greater than one but less than the initial value, reflecting the loss in permeability and/or area.

Argüello (1990) showed that stress relief is not uniform below an individual room, but is greater where the room intersects a drift and is less at the back of a room where no further excavation has occurred. A test conducted near the front of a room might, therefore, show one flow dimension until the pressure transient propagated into the higher permeability region below the intersection of the room with its access drift, at which time a higher flow dimension would be evident. The tests of MB140 in L4P51 may provide an example of this. Conversely, a test conducted near the back of a room might show a decreasing flow dimension for some period of time as the pressure transient propagates into the lower permeability rock beyond the footprint of the excavation. At some later time, the flow dimension might increase if the pressure transient propagated into a higher permeability region toward the front of the room. Flow dimensions should also be expected to change with time where hydraulic properties are pressure-dependent. Nonuniform (i.e., high-gradient) pressure fields in regions with varying hydraulic properties must also affect inferred flow dimensions. 


\subsection{Tests Around Room $Q$}

Room $Q$ was mined at the western end of the $S 90$ drift in an area that should have been minimally, if at all, affected by the presence of the other WIPP excavations (Figure 3). Room Q was mined using a tunnel-boring machine to create a $2.9-\mathrm{m}$-diameter cylindrical room $109 \mathrm{~m}$ long. Before the room was mined, 15 boreholes were drilled into the west rib of the alcove at the end of the S90 drift and instrumented to allow pore pressure and permeability testing before and after the mining. The holes were drilled so that they terminated in three lines, comprising five holes each, vertically above (QPP01-05), vertically below (QPP11-15), and horizontally north (QPP21-25) of the eventual centerline of the room (Figure 4). All of the boreholes terminate $22.9 \mathrm{~m}$ along the length of the room in a plane normal to the axis of the room. In each of the three arrays, the boreholes were designed to terminate at distances of approximately $2.4,3.3,4.6$, 7.6, and $13.7 \mathrm{~m}$ from the centerline of the room. The tests conducted in these holes before Room Q was mined should provide the best representation of far-field properties of any of the permeability tests performed. The parameter values presented below were derived by Domski et al. (1996) assuming a flow dimension of two; no flow-dimension analysis of these tests has been performed.

Four anhydrite layers were isolated in the Room Q boreholes: MB138 (QPP01), MB139 (QPP13), anhydrite "b" (QPP03), and anhydrite "c" (QPP11). All four anhydrites showed immediate pressure-buildup responses when the test zones were shut in. Estimated pre-mining pore pressures of MB138, MB139, and anhydrite " $b$ " ranged from 12.4 to $14.8 \mathrm{MPa}$ (Figure 4). The anhydrite "c" test interval was not shut-in long enough for an estimate of the pre-mining pore pressure to be made. The inferred pre-mining permeabilities of MB139 and anhydrite "b" 


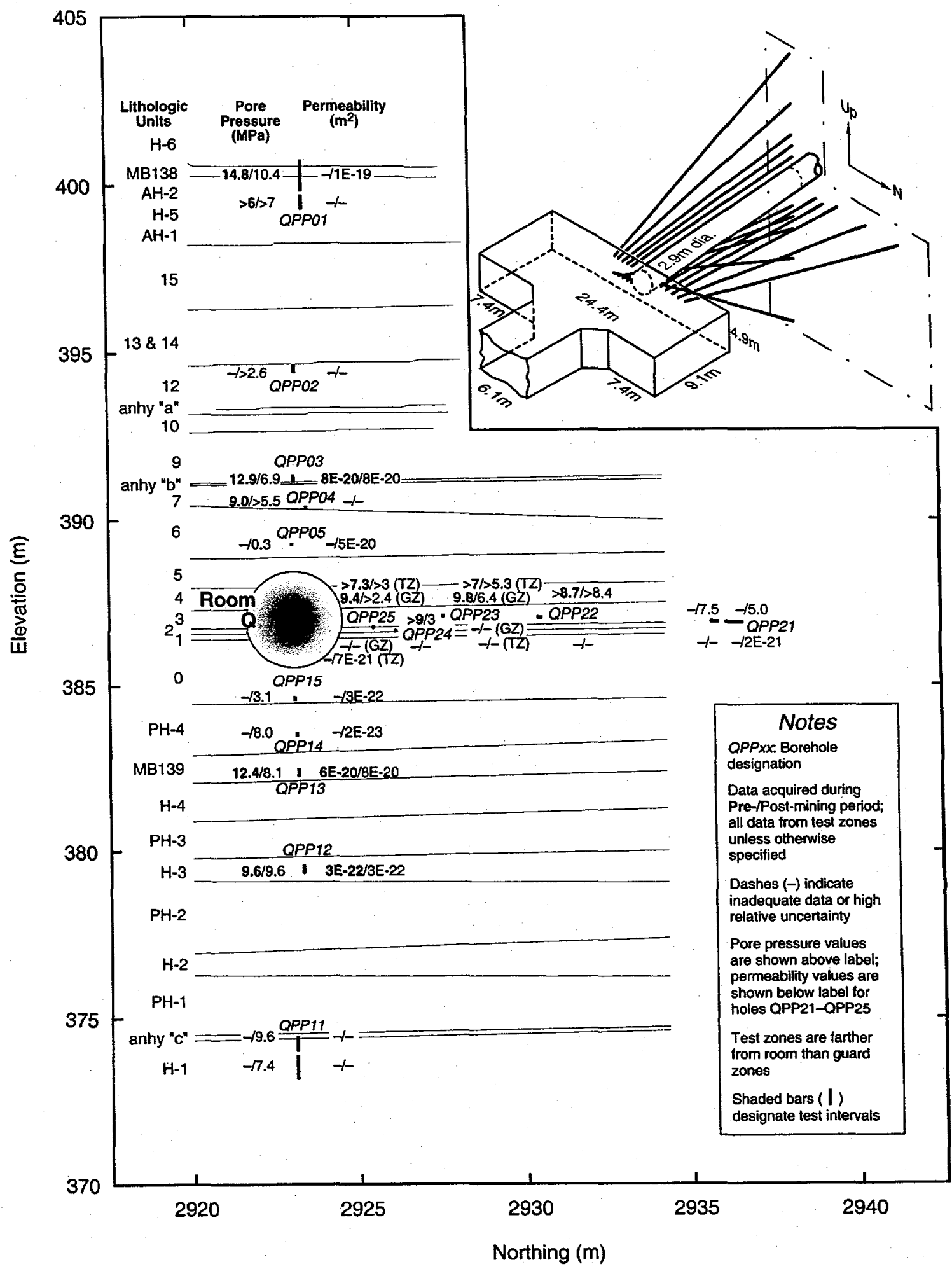

TRI-61 19-233-3

Figure 4. Stratigraphic locations of test boreholes around Room Q and interpreted hydraulic

properties. 
were $6 \times 10^{-20}$ and $8 \times 10^{-20} \mathrm{~m}^{2}$, respectively. The pre-mining data from MB138 and anhydrite "c" were inadequate for permeability estimation. After Room Q was mined, estimated pore pressures decreased and inferred permeabilities increased insignificantly. Post-mining pore pressures for the four anhydrite layers ranged from 6.9 to $10.4 \mathrm{MPa}$. Inferred permeabilities for both MB139 and anhydrite " $\mathrm{b}$ " were $8 \times 10^{-20} \mathrm{~m}^{2}$, and the permeability of MB138 was inferred to be $1 \times 10^{-19} \mathrm{~m}^{2}$ (Figure 4).

Twelve halite intervals were isolated in the Room $\mathrm{Q}$ boreholes. Of these, six (map units 12 and 13 [QPP02], 6 [QPP05], H-1 [QPP11], PH-4 [QPP14], 0 and PH-4 [QPP15], and 2 and 3 [QPP21]) showed no clear pore pressure or permeability before Room Q was mined. The remaining six intervals showed clear evidence of both permeability and pore pressure. These intervals (map units 6 and 7 [QPP04], H-3 [QPP12], and 2 and/or 3 [QPP22-25]) had apparent pore pressures of approximately 9 to $10 \mathrm{MPa}$. The only pre-mining permeability that could be estimated with confidence was $3 \times 10^{-22} \mathrm{~m}^{2}$ for H-3 in QPP12. Domski et al. (1996) also attempted simulations of the pressure data from the intervals that showed no clear pore pressure or permeability. They found that those intervals could have permeabilities on the order of $10^{-24}$ to $10^{-22} \mathrm{~m}^{2}$ and not show obvious pressure-buildup responses toward the ambient pore pressure over the tens of days that pressure measurements were made. Thus, small but nonzero permeabilities are not inconsistent with the observed data.

After Room Q was mined, all of the halite intervals showed clear evidence of pore pressure and permeability. With the exception of H-3 in QPP12, all halite intervals for which pre-mining pore pressures could be estimated had lower pore pressures after mining. The intervals for which pore 
pressures could only be estimated after mining had extrapolated pore pressures of $9.6 \mathrm{MPa}$ or less. Pore pressures appeared to decrease with increasing proximity to Room $Q$. In some intervals, post-mining pore pressures appeared to continue to decrease with time. The postmining permeabilities that could be estimated for halite intervals ranged from $2 \times 10^{-23}$ to $5 \mathrm{x}$ $10^{-20} \mathrm{~m}^{2}$ (Figure 4). The permeability of the H-3 interval in QPP12 did not appear to change as a result of mining Room $\mathrm{Q}$. Comparing the post-mining responses of the other halite intervals to the pre-mining responses, Domski et al. (1996) concluded that permeabilities had increased by at least two orders of magnitude.

The majority of the post-mining extrapolated pore pressures $\geq 6 \mathrm{~m}$ from the surface of Room $\mathrm{Q}$ ( $>5$ radii from the room center) were between approximately 9 and $10 \mathrm{MPa}$. The pore pressure in QPP12 before mining also fell in this range. Perhaps this pore pressure reflects the mean stress at a distance of $23 \mathrm{~m}$ from the instrument alcove at the end of the $\$ 90$ drift with no influence from Room Q. Two to $3 \mathrm{~m}$ from the surface of Room $\mathrm{Q}$ (2.1 to 3.3 radii), post-mining pore pressures were 3 to $8 \mathrm{MPa}$, and within $1 \mathrm{~m}$ of Room $\mathrm{Q}(<1.7$ radii), pore pressures were 0.3 to $3 \mathrm{MPa}$.

\section{Summary of Room Q Observations}

The pre-mining observations around Room $Q$ do not provide a simple picture of far-field hydraulic properties. All four of the anhydrite intervals tested showed permeability and pore pressure. Half (six) of the halite intervals tested showed permeability and pore pressure, and half did not. Extrapolated pore pressures in the six permeable halite intervals were only 9 to $10 \mathrm{MPa}$, not the $15 \mathrm{MPa}$ estimated as the undisturbed lithostatic load at the WIPP horizon (Wawersik and 
Stone, 1989). Thus, stress relief related to the presence of the WIPP excavations may have affected all of the test locations even before Room Q was mined. Extrapolated pore pressures in the anhydrites (12.4 to $14.8 \mathrm{MPa}$ ) were closer to the estimated lithostatic pressure than those in the halite, suggesting that anhydrite may be less sensitive to stress relief than halite.

After the mining of Room Q, anhydrite permeabilities were little changed but pore pressures were significantly reduced. All halite intervals showed pore-pressure responses, indicating the presence (or creation) of permeability. Other than the qualitative observation that permeability appeared to have been created in some halite intervals by the mining of Room Q, the data are inadequate to say more about the effects of mining on permeability. No conclusions can be drawn about the effects of mining on flow dimensions because no flow-dimension analysis has been performed of these tests. Halite pore pressures generally increased with distance from Room Q.

\subsection{Tests at Other Locations}

Forty-three intervals were isolated and monitored and/or tested in 12 boreholes drilled at various locations in the WIPP excavations (Figure 3). Twenty of the intervals included anhydrite layers, and the other 23 intervals included different halite layers. The data from these intervals are discussed and interpreted in Beauheim et al. (1991; 1993) and Roberts et al. (1999). These tests were conducted at various distances and orientations around excavations of different sizes and ages. Thus, the results represent a combination of effects not easily disentangled. 
Four of the intervals would not hold brine under pressure: C2H01-A guard zone (map unit 6), S1P71-A guard zone (MB139), and S1P73-A guard zone (anhydrite "b") and test zone (anhydrite "a"). The C2H01-A and S1P71-A guard zones were 0.5 to $1.6 \mathrm{~m}$ and 1.2 to $2.3 \mathrm{~m}$, respectively, below the floors of excavations (Figures 5 and 6). The S1P73-A guard and test zones were 1.5 to $2.6 \mathrm{~m}$ and 3.4 to $4.8 \mathrm{~m}$, respectively, directly above the back (roof) of Room 7 in Panel 1 (Figure 6). Floor heave at the first two locations and roof sag at the last location probably increased permeability and porosity beyond the capacity of the formation to keep it filled with brine.

Three of the intervals showed no pressure response indicative of permeability or pore pressure: C2H03 guard zone and test zone (both map unit 9), and SCP01-A guard zone (map unit $\mathrm{PH}-4$ ). The test and guard zones in $\mathrm{C} 2 \mathrm{H} 03$ were 7.9 to $9.1 \mathrm{~m}$ and 5.9 to $6.9 \mathrm{~m}$, respectively, from the rib of Room C2 (Figure 5). The guard zone in SCP01 was 8.8 to $9.9 \mathrm{~m}$ from the core-storage library. Both of the tested units are relatively pure halite. PH-4 is also the unit isolated in QPP14 that showed no pressure response prior to excavation of Room Q.

The other 36 isolated intervals showed clear pressure-buildup responses when they were shut-in, although the data were not adequate in every case for estimation of permeability and/or pore pressure. Permeabilities were estimated for 18 of the intervals (six halite and 12 anhydrite intervals) and pore pressures were estimated (or bounded) for 31 intervals (15 halite and 16 anhydrite intervals). Estimated halite permeabilities ranged from $1 \times 10^{-21} \mathrm{~m}^{2}$ in the C2H01-B test zone (map unit 0 ); 4.5 to $5.6 \mathrm{~m}$ below Room $\mathrm{C} 2$, to $3 \times 10^{-16} \mathrm{~m}^{2}$ in the $\mathrm{C} 2 \mathrm{H} 01-\mathrm{A}$ test zone (map units 4 and 5), 2.1 to $2.9 \mathrm{~m}$ below Room C2 (Figure 5). Estimated anhydrite permeabilities 

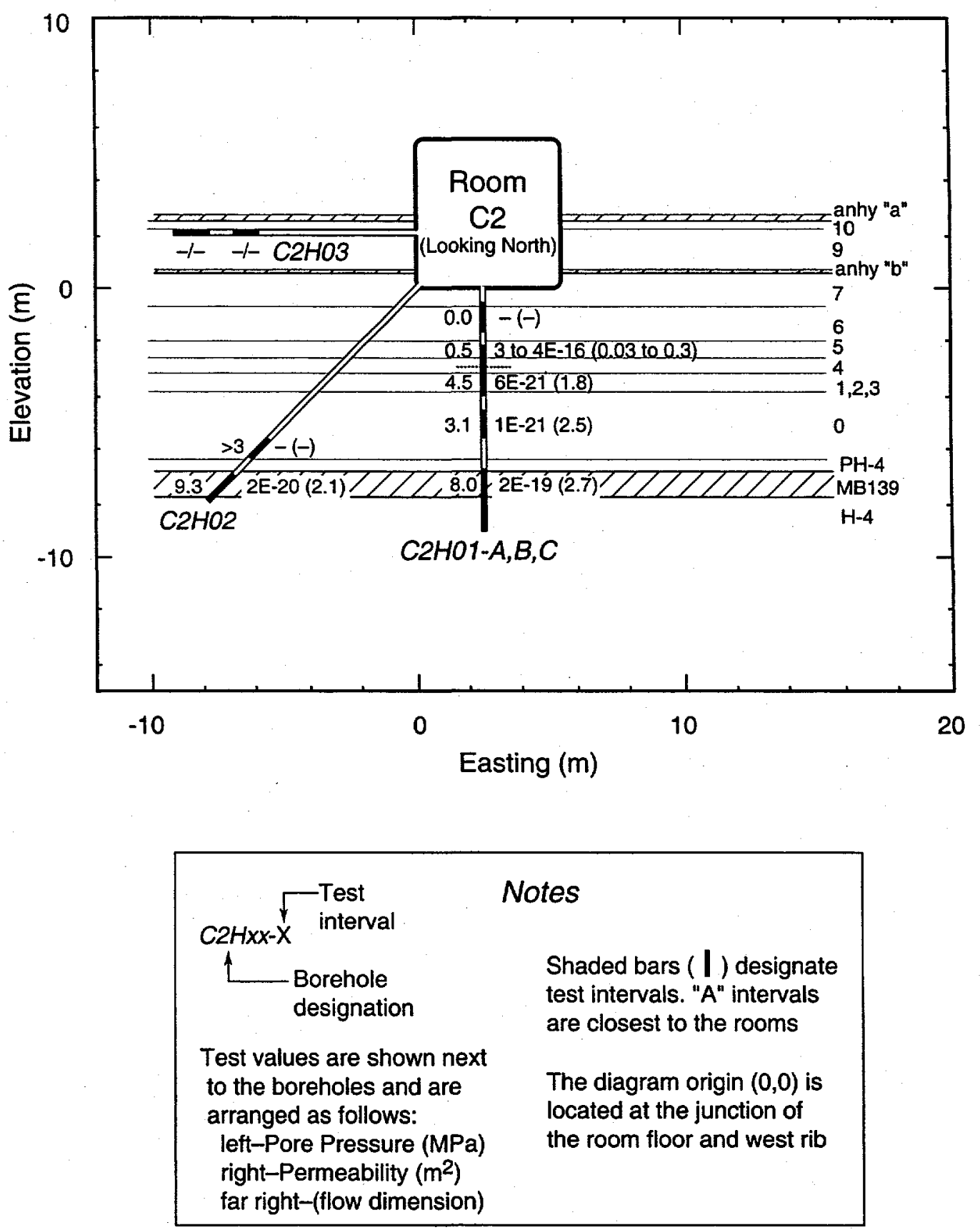

TR1-6115-1021-0

Figure 5. Stratigraphic locations of test boreholes around Room C2 and interpreted hydraulic properties. 


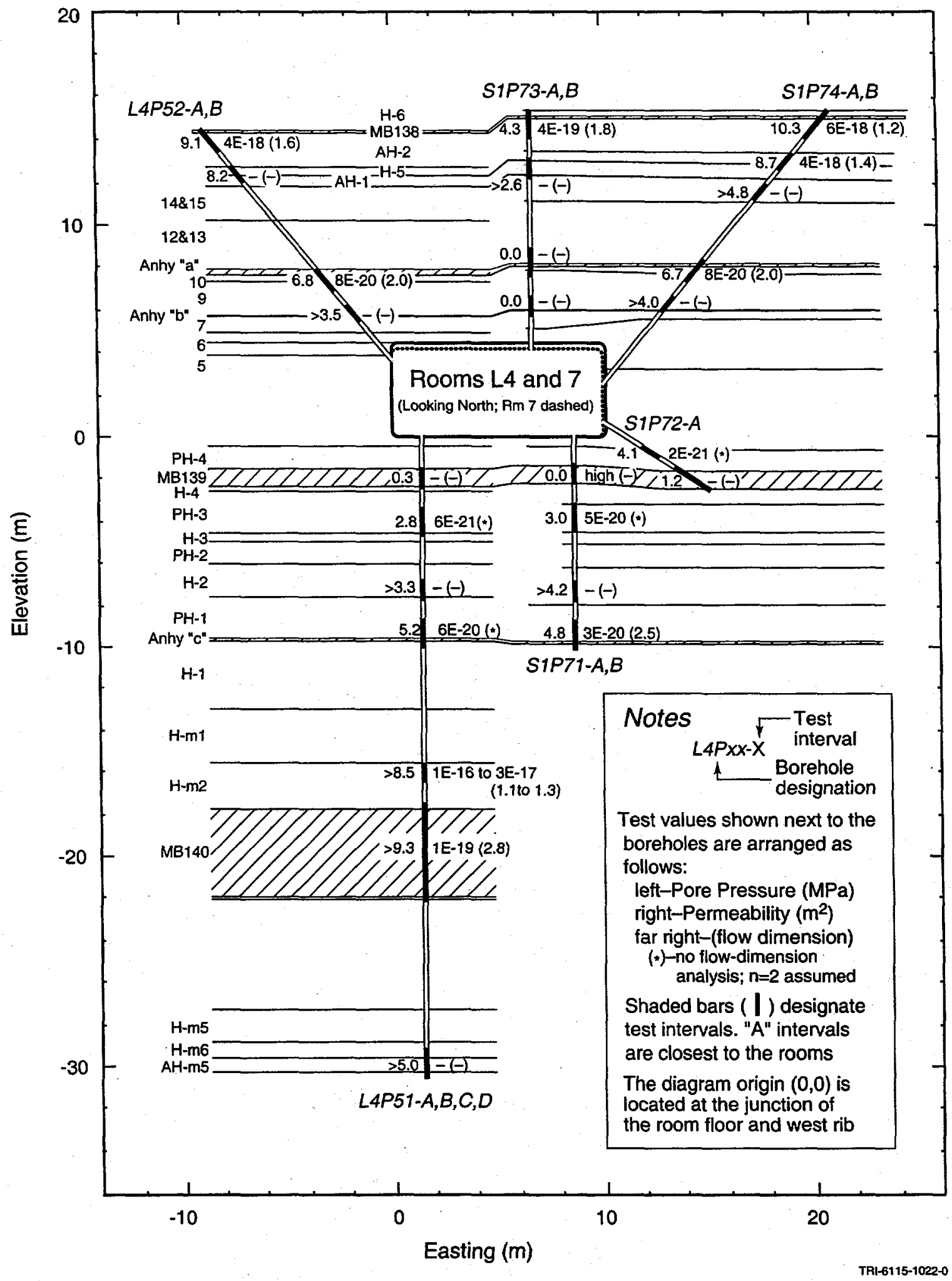

Figure 6. Stratigraphic locations of test boreholes around Room L4 and Room 7 in Waste Panel

1 and interpreted hydraulic properties. 
ranged from $2 \times 10^{-20} \mathrm{~m}^{2}$ in the $\mathrm{C} 2 \mathrm{H} 02$ test zone (MB139), 9.5 to $10.7 \mathrm{~m}$ from Room $\mathrm{C} 2$ in a borehole angled downward under the rib, to $9 \times 10^{-18} \mathrm{~m}^{2}$ in the SCP01-A test zone (MB139), 10.7 to $14.8 \mathrm{~m}$ below and away from a back corner of the core-storage library. Nonzero halite pore pressures ranged from 0.5 MPa in the C2H01-A test zone (Figure 5) to 8.7 MPa in S1P74-B test zone 2 (map units AH-1 [clay J] and H-5), 13.2 to $14.3 \mathrm{~m}$ angled upwards and away from Room 7 in Panel 1 (Figure 6). Nonzero anhydrite pore pressures ranged from $0.3 \mathrm{MPa}$ in the L4P51-A guard zone (MB139), 1.5 to $2.4 \mathrm{~m}$ directly below Room L4 (Figure 6), to $13.5 \mathrm{MPa}$ in the SCP01-A test zone.

In some cases, permeabilities were found to be dependent on the pressures at which the tests were conducted. As the test fluid pressure increased, the effective stress decreased and permeability increased. This is interpreted as fracture apertures increasing with decreasing effective stress. Pressure-dependent permeability was observed in both anhydrite and halite layers.

\subsection{Small-Scale Mine-By}

Stormont et al. (1991a, b) performed an experiment designated the Small-Scale Mine-By to determine the effects of excavation on saturation and permeability of the surrounding rock. They drilled an array of 124.8 -cm-diameter boreholes to a depth of $8 \mathrm{~m}$ below Room L1 (Figure 3) at different radial distances from where they would later drill a 96.5 -cm-diameter hole. They isolated the lower $65 \mathrm{~cm}$ of each borehole (map unit $\mathrm{H}-2$ ) and filled six of the holes with brine and six with gas, all pressurized to $2 \mathrm{MPa}$. Testing showed brine pore pressures of 2.7 to 3.6 $\mathrm{MPa}$, brine permeabilities ranging from $1 \times 10^{-22}$ to $2 \times 10^{-20} \mathrm{~m}^{2}$, and zero permeability to gas. 
After the $96.5-\mathrm{cm}$ hole was drilled in the center of the test array, additional tests were performed in the boreholes. These tests showed that permeabilities within approximately two radii ( $2 \mathrm{r}$ ) of the center of the $96.5-\mathrm{cm}$ hole increased with proximity to the hole, with a maximum increase of nearly five orders of magnitude to $9 \times 10^{-16} \mathrm{~m}^{2}$ at $1.25 \mathrm{r}$. Pore pressures were reduced out to $3 \mathrm{r}$. Within approximately $1.5 \mathrm{r}$, partially saturated conditions and measurable gas permeability developed.

The tests described by Stormont et al. (1991a, b) were all conducted over an approximately 250day period after the $96.5-\mathrm{cm}$ hole was drilled, so did not evaluate any continuing timedependence of hydraulic properties. The low initial pore pressures also indicate that the test horizon had been affected by stress relief resulting from the excavation of Room L1. Thus, the responses observed by Stormont et al. (1991a, b) were probably superimposed on an alreadydisturbed rock mass. Nevertheless, the test results clearly showed the development of a partially saturated zone around the $96.5-\mathrm{cm}$ hole, increased permeability, and decreased pore pressure.

\section{Observed Spatial Variations in Hydraulic Properties}

The values of permeability and pore pressure inferred from the tests in the WIPP excavations are discussed below in the context of the foregoing discussion and plotted versus distance from an excavation. We cannot be certain that any of our test results are representative of conditions in the far field, completely unaffected by the presence of the WIPP excavations. The permeability of anhydrite is typically higher than that of halite. Pore pressure is demonstrably related to distance from an excavation. 


\subsection{Permeability}

Figure 5 shows the intervals tested in boreholes drilled from Room $\mathrm{C} 2$ and the properties inferred from the tests. The tests were all performed roughly 4.5 to 5.5 years after the mining of Room C2. In MB139, both the permeability and flow dimension were higher directly beneath the room $(\mathrm{C} 2 \mathrm{H} 01-\mathrm{C})$ than beneath the room pillar $(\mathrm{C} 2 \mathrm{H02})$. This probably reflects fracture dilation and/or increased fracturing due to stress relief directly beneath the room. In contrast, halite permeability decreased while the flow dimension increased with distance below the room. We speculate that excavation effects caused increased, but directional, permeability close to the room. The high flow dimension (2.5) observed in the $\mathrm{C} 2 \mathrm{H} 01-\mathrm{B}$ test zone may indicate that the tested unit, map unit 0 , has little anisotropy between horizontal and vertical permeability and that sections of the unit above and below the isolated interval contributed to the observed response. No pore-pressure response indicative of permeability was observed in the clean halite of map unit 9 in the room pillar (C2H03).

Figure 6 shows the intervals tested in boreholes drilled from Rooms L4 and 7 (Waste Panel 1) and the properties inferred from the tests. MB138 had the lowest permeability and the highest flow dimension where it was tested directly above a room (S1P73-B). We would have expected to observe both the highest permeability and flow dimension in this position because of stress relief. However, the S1P73-B testing was performed approximately 3.2 years after the excavation of Room 7, whereas the S1P74-B and L4P52-B tests of MB138 above room pillars were performed approximately seven and four years after excavation of Rooms 7 and LA, respectively. Hence, the age of the excavations at the time of testing may have had some effect

on the results. The units that were tested in two boreholes with similar orientations generally had 
similar permeabilities and flow dimensions. The L4P51-B and S1P71-B tests of anhydrite "c", which were performed when the rooms were of similar ages (Room L4 was 1.7 to 2.6 years old at the time of testing while Room 7 was 1.7 to 2.2 years old), provided similar results. The L4P52-A and S1P74-A tests of anhydrite "a" provided similar results, even though Room L4 was 2.2 to 3.2 years old at the time of testing while Room 7 was 4.4 to 5.3 years old. The largest difference in permeabilities, nearly an order of magnitude, was observed in the LAP51-A and S1P71-A tests of map unit PH-3. The tests were performed at similar times relative to the ages of the rooms (9-15 months and 8-13 months), so we attribute the difference in permeabilities to natural heterogeneity.

Figure 7 presents a plot of average permeabilities versus radius-normalized test-interval distances from an excavation from GTFM simulations of the tests discussed in Beauheim et al. (1991, 1993), Domski et al. (1996), and Roberts et al. (1999). The distances were normalized by dividing the distance of each test interval along its borehole by the radius of the room in which the borehole originates, where the room radius is defined as one-half the diagonal distance across the room in cross section. (Distances for the QPPxx test intervals are normalized with respect to either the instrumentation alcove from which the holes were drilled or Room $Q$, whichever was closer in terms of radii at the time of testing.) The permeabilities of several of the tested units shown on Figure 7 are believed to be pressure-dependent. The permeabilities shown on Figure 7 for these tests are the permeabilities corresponding to the static pore pressures in the tested units prior to testing. Testing sequences performed in the L4P51-C1 guard zone and LAP51-C2 test zone 2 were tests of the same halite interval over different time periods, so the estimated permeability values are shown as a range for a single interval on the figure. Ranges are also 


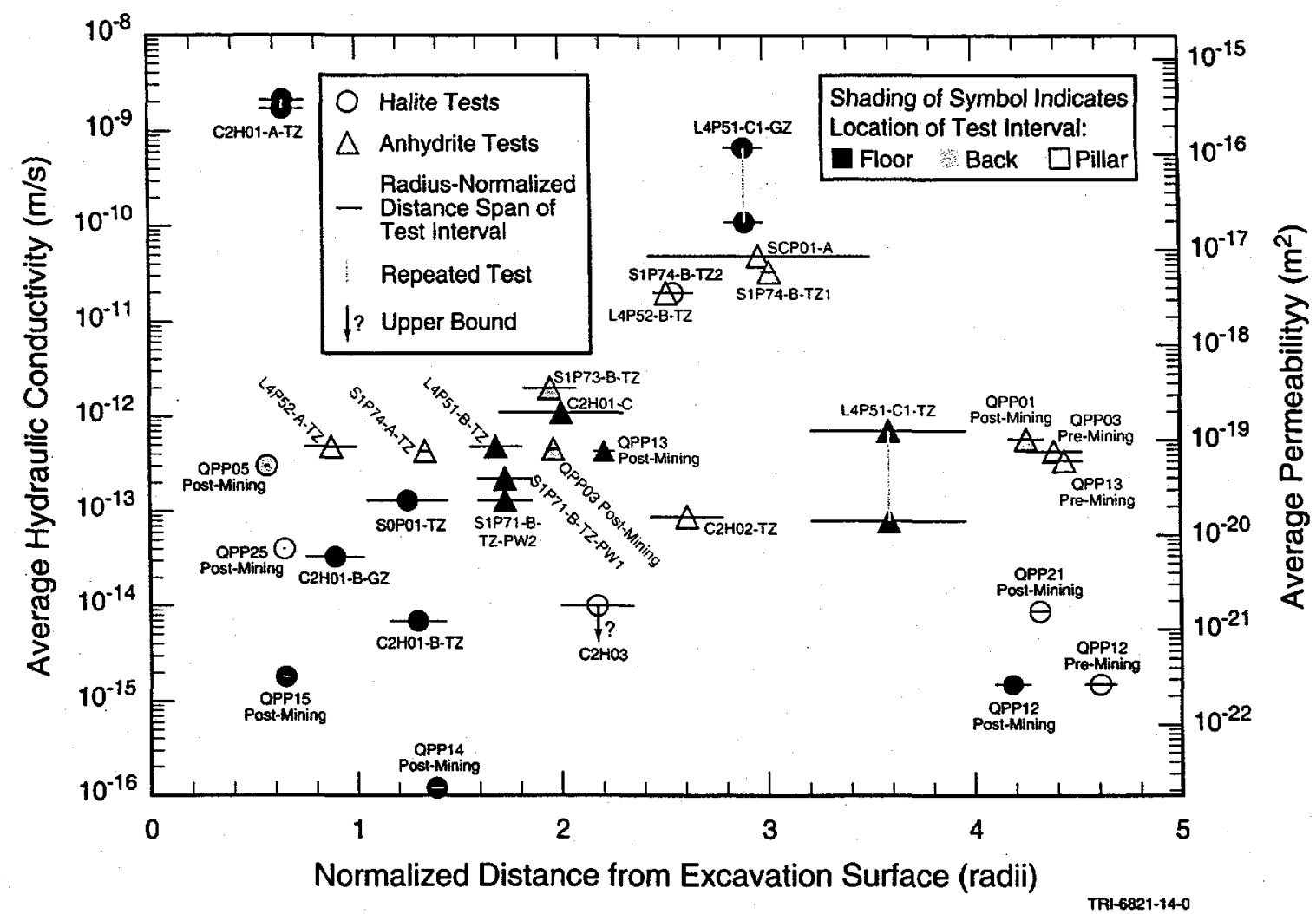

Figure 7. Interpreted average permeabilities versus radius-normalized distances from

excavations.

shown for other intervals (e.g., MB140 in L4P51) for which different permeability estimates were obtained.

Figure 7 shows 14 values of halite permeability and 16 values of anhydrite permeability. No correlations are evident between estimated halite or anhydrite permeability and radiusnormalized distance from an excavation. The lowest estimate of halite permeability, $2 \times 10^{-23}$ $\mathrm{m}^{2}$, is from QPP14 after the mining of Room Q, approximately 1.4 room radii from the excavation. All halite permeabilities from test intervals two or more room radii from an excavation are higher than this value. The highest halite permeability estimate, $3 \times 10^{-16} \mathrm{~m}^{2}$, is from the C2H01-A test zone, approximately 0.6 room radii below an excavation. The lowest 
estimate of anhydrite permeability, $2 \times 10^{-20} \mathrm{~m}^{2}$, is from the $\mathrm{C} 2 \mathrm{H} 02$ test zone, approximately 2.4 to 2.8 room radii from the excavation in a borehole angled downward under the rib. All five estimates of anhydrite permeability from distances greater than three room radii, both in angled and vertical boreholes, are greater than this value. The highest estimate of anhydrite permeability, $9 \times 10^{-18} \mathrm{~m}^{2}$, is from MB139 in the SCP01-A test zone, approximately 2.4 to 3.5 room radii below and beyond an excavation.

No correlations between permeability and distance from an excavation can be defined from Figure 7 even when the angled-hole tests are considered separately from the vertical-hole tests. This is not to argue that permeability is not affected by the excavations. As discussed in Section 3.2, changes in the stress field around excavations likely cause both increases and reductions in permeability at different locations and times. But both halite and anhydrite permeabilities seem to range over several orders of magnitude just because of variations in mineralogy and other natural heterogeneity. Excavation-induced changes superimposed on this natural variation cannot be identified without pre- and post-excavation testing at each specific location.

As noted by Beauheim et al. (1993), estimated permeabilities such as those presented in Figure 7 represent average values assuming that the tested intervals are homogeneous. If the observed responses are dominated by singular features (such as fractures) rather than by uniform properties, then the average permeability values shown in Figure 7 might not be meaningful. Another factor complicating the comparison of permeability values is the relationship between permeability and flow dimension. The expression "flow dimension" is used in this paper to represent the combined effects of changes in permeability and flow geometry. Thus, the reported 
value of permeability depends on the value used for flow dimension. For a given response, as the value of flow dimension used to interpret that response increases, the estimated permeability decreases, and vice versa. Even when flow dimension is clearly defined, we have no way of knowing without additional information if the dimension is caused by changes in permeability or changes in the geometry of flow. The reported permeability values are based on the following assumptions and are estimated using a multi-step analysis process. The measured formation response is matched initially using constant values of $K$ and $S_{s}$ and distance-varying $n[n(r)]$, if necessary. The flow dimension in the next step is then assumed to be constant and equal to the late-time value determined in the previous step. Corresponding $K(r)$ and $S_{s}(r)$ functions are calculated such that the simulated response is identical to that obtained with $n(r)$ and constant $K$ and $S_{s}$. The late-time values of $K(r)$ and $S_{s}(r)$ are constants that correspond to the specified value of $n$. These late-time values of $K$ and $S_{s}$ are the reported values, assumed to be the representative values beyond the DRZ (skin) around the test borehole. These assumptions may or may not be valid.

Only five of fourteen halite permeabilities are equal to or greater than $10^{-20} \mathrm{~m}^{2}$ : those from LAP51-C1-GZ, C2H01-A, S1P74-B-TZ2, QPP05 post-mining, and S0P01-TZ. The L4P51-C1 guard zone was unlike any other zone tested and the reason for high permeability in halite H-m2 is unknown. The other four halite permeabilities greater than $10^{-20} \mathrm{~m}^{2}$ all come from test intervals that are within approximately 2.6 room radii of an excavation and/or contain significant clay seams. The C2H01-A test interval was approximately 0.6 room radii below the floor of Room C2, a location where excavation-induced disturbance would be expected. The C2H01-A tests were also the first of the permeability tests to be performed, and later experience showed 
that pulse tests conducted, like these, over a 0 to $3.5 \mathrm{MPa}$ absolute pressure range are likely to be significantly affected by pressure-dependent test-zone compressibility. The data necessary to evaluate test-zone compressibility were not collected during the C2H01-A testing and, therefore, the parameters estimated from those tests are considered to have high uncertainty. The S1P74-B test zone 2 interval was approximately 2.5 room radii from the excavation, but included AH-1, the most clay-rich halite interval near the repository horizon. The QPP05 test interval was less than 0.6 room radii from Room $Q$, and the SOP01 test interval, 1.0 to 1.4 room radii from an excavation, included clay D.

Permeability values for anhydrite range from approximately $10^{-20}$ to $10^{-17} \mathrm{~m}^{2}$. The three values greater than $10^{-18} \mathrm{~m}^{2}$ were from tests conducted in boreholes angled away and at distances of 2.4 or more room radii from the excavations (SCP01-A, S1P74-B, and L4P52-B), suggesting that the inferred high permeabilities are not necessarily caused by responses to the excavations, but may be representative of far-field properties.

\subsection{Pore Pressure}

Figure 8 presents a plot of estimated formation pore pressures versus radius-normalized testinterval distances from an excavation for 40 halite intervals and 26 anhydrite intervals (Beauheim et al., 1991, 1993; Domski et al., 1996; Roberts et al., 1999). The pore pressures were estimated from GTFM simulations or extrapolated from maximum observed pressures in a zone for all of the Salado permeability tests. A general trend of increasing pore pressure with increasing distance from an excavation can be seen for both anhydrite and halite intervals. Figures 4, 5, and 6, show the same pattern of increasing pore pressures with increasing distance 


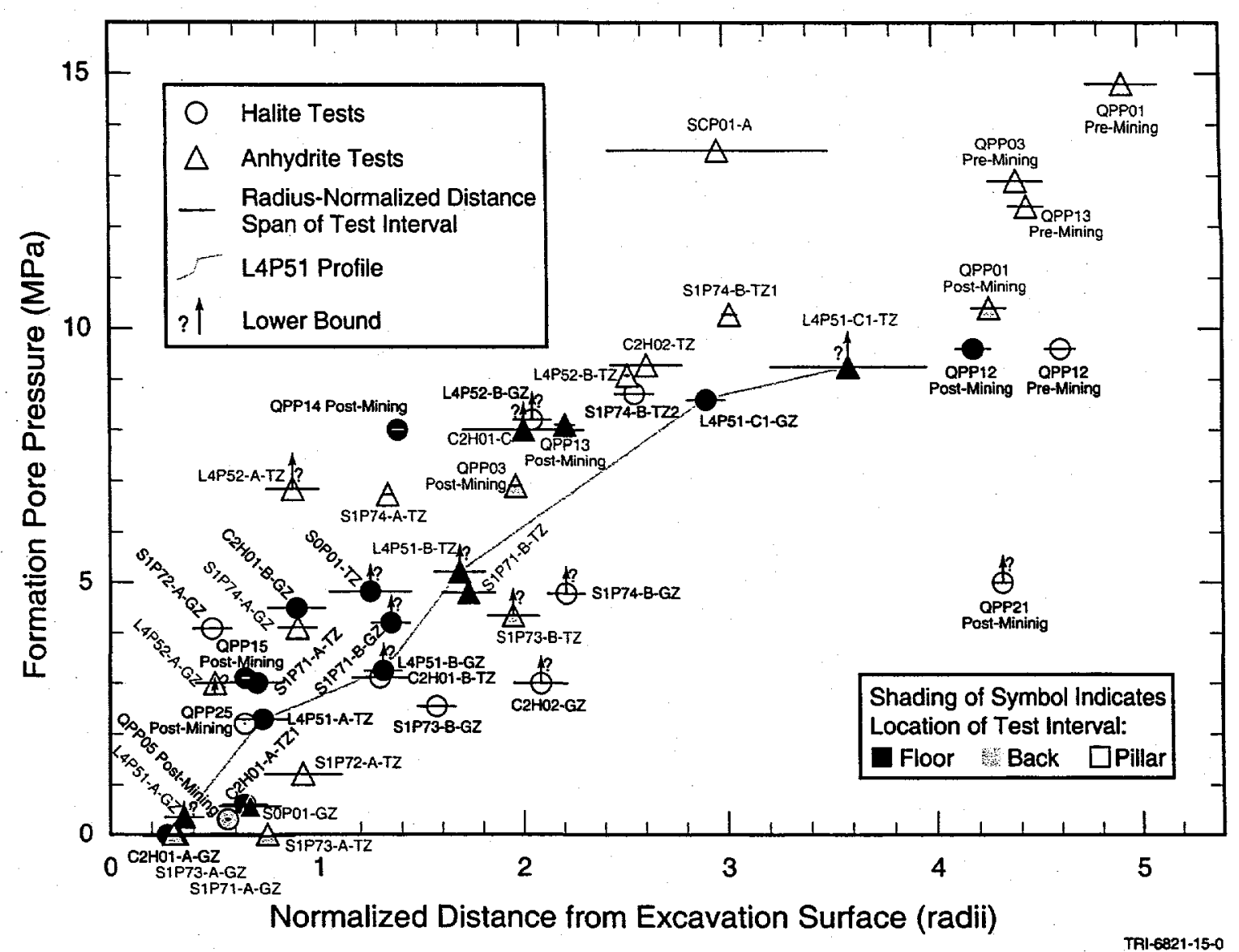

Figure 8. Interpreted pore pressures versus radius-normalized distances from excavations.

from Room Q, Room C2, and Rooms L4 and 7, respectively. Pore-pressure estimates are available from more intervals (six) in borehole L4P51 than in any other hole, and show a clear trend of increasing pressure with distance from the excavation. (Only a lower bound on pore pressure is available from the seventh (D) interval in L4P51.)

Pore pressures tend to be most reduced directly above and below excavations, as shown by atmospheric-pressure (unsaturated) conditions encountered in two test intervals 0.2 to 0.4 room radii into the floor and in two test intervals 0.2 to 0.8 room radii into the back of excavations. With one exception, the highest pore pressures shown in Figure 8 at any normalized distance are from within pillars rather than directly above or below an excavation. Figure 6 , which presents 
data from around two rooms of similar size, clearly shows the increased depressurization above and below excavations compared to within pillars.

The highest pore pressures ( $>12 \mathrm{MPa}$ ) have all been measured in holes drilled outward into virgin rock from the extreme edges of the WIPP excavations. The highest pore pressure extrapolated for any test interval is $14.8 \mathrm{MPa}$ for MB138 in QPP01 before the mining of Room Q. This value is equal to the estimated lithostatic pressure at the WIPP repository horizon (Wawersik and Stone, 1989), but we note that it is an extrapolated value only. The highest pressure actually observed in QPP01 was approximately 10.2 MPa (Domski et al., 1996). Pressures of 11.4 MPa (extrapolated to $12.9 \mathrm{MPa}$ ), 10.5 MPa (extrapolated to $12.4 \mathrm{MPa}$ ), and 11.8 MPa (extrapolated to 13.5 MPa) were observed in QPP03 (anhydrite "b"), QPP13 (MB139), and SCP01 (MB139) (Domski et al., 1996; Roberts et al., 1999). Thus, the highest observed (and extrapolated) pressures have been in anhydrite layers. In comparison, the highest pressures ever observed in halite are approximately $8.5 \mathrm{MPa}$ (extrapolated to $9.6 \mathrm{MPa}$ ) in QPP12, 8.7 MPa in QPP22, and 8.8 MPa in QPP24 (Domski et al., 1996).

\subsection{Discussion}

Wawersik et al. (1997) interpret hydraulic-fracturing data to show that the stress state (and presumably the pore pressure) in MB140, 24 to $29 \mathrm{~m}$ ( $\sim$ six room radii) below the floor of Room C1, was clearly affected by the excavation. Wawersik and Stone (1989) reported that an isotropic stress field in halite at the WIPP, representative of conditions unaffected by the presence of excavations, was encountered only at distances greater than $50 \mathrm{~m}$ laterally away from the excavations. Therefore, as no tests have been conducted more than $30 \mathrm{~m}$ from 
excavations, none of them may be outside the region of stress relief around the WIPP repository and we cannot be certain that any of the inferred hydraulic properties are representative of conditions in the far field.

Given this qualification, we nevertheless conclude that the permeability of anhydrite is generally higher than that of halite. The lowest anhydrite permeability inferred, $2 \times 10^{-20} \mathrm{~m}^{2}$, is nearly three orders of magnitude higher than the lowest halite permeability, $2 \times 10^{-23} \mathrm{~m}^{2}$. In general, anhydrite permeabilities are greater than $10^{-20} \mathrm{~m}^{2}$ and halite permeabilities are generally less than that value. The consistency of the inferred anhydrite permeability values over a wide range of pore-pressure conditions suggests that far-field values would likely be similar. Appropriate values for the permeability of halite in the far field are less certain.

The pore pressure in a medium, such as halite, that undergoes creep might be expected to be equal to the lithostatic pressure because creep will continue until the deviatoric stress is zero. Pore pressures in anhydrite interbeds overlain and underlain by halite might also be expected to be equal to lithostatic pressure. A pore pressure approaching $15 \mathrm{MPa}$, corresponding to the estimated undisturbed lithostatic pressure at the WIPP horizon (Wawersik and Stone, 1989), has been never been observed in any test interval, although it has been extrapolated from pressure data from MB138 in QPP01 before the mining of Room Q (Domski et al., 1996). Even at the greatest distance from the WIPP excavations at which tests have been conducted, $24 \mathrm{~m}$, observed or extrapolated halite pore pressures are less than $10 \mathrm{MPa}$ (Figure 8). Because halite has lower elastic moduli than anhydrite (Beauheim et al., 1991), we would expect halite to show more of a pore-pressure reduction in response to stress relief than anhydrite. Thus, observed pore pressures 
are consistent with all testing having been conducted within the region of stress relief around the WIPP excavations.

\section{Evaluation of Data and Conceptual Models}

\subsection{Far-Field Permeability}

All six anhydrite layers tested have shown pressure responses indicative of permeability at all times and locations. Inasmuch as no anhydrite testing has been performed more than $24 \mathrm{~m}$ (or 4.6 room radii) from an excavation, this does not prove that all anhydrites are permeable in the far field. However, coupled with the observation of open bedding-plane fractures that are not thought to be related to the presence of the WIPP excavations (Borns, 1985), we believe that anhydrite is in fact permeable in the far field.

Eight halite intervals have been found that showed no pressure response indicative of permeability and pore pressure. These intervals comprised relatively pure halites at distances of 6 to $24 \mathrm{~m}$ ( 1.6 to 4.7 room radii) from the nearest excavations. At all other locations where halite has been tested, including $29 \mathrm{~m}$ (5.3 room radii) from the nearest excavation, pore pressure and permeability have been observed. In some cases, this may be a result of excavation-induced changes. In other cases, however, particularly the halite intervals 23 and $29 \mathrm{~m}$ (4.5 and 5.3 room radii) from excavations, we do not believe that the observed permeabilities could have been caused by excavation-induced changes. We believe that some halite intervals, particularly those with greater than a few percent impurities, naturally possess an interconnected pore network. All other things being equal, we would expect permeability to increase with increasing impurities in 
the halite, but this cannot be proved with the available data. Argillaceous halite may be the most permeable halite, because the clay may itself form an interconnected network.

Observations in boreholes drilled through the Salado from land surface show that, whether confined to the anhydrite layers or including some impure halite layers, some portion of the Salado must have far-field permeability. Drillstem tests performed in the Salado in seven boreholes showed little flow but clear pressure buildups (Mercer, 1987). Likewise, two boreholes registered positive pressure buildups at the wellhead indicative of brine levels above ground surface when the Salado was the only interval open to the wells (Sandia National Laboratories and D'Appolonia Consulting Engineers, 1982). These wells are unquestionably within the far field with respect to any excavations, and the pressure responses observed in these wells clearly demonstrate permeability.

\subsection{Percolation Model}

The responses observed during the tests conducted of halite intervals in boreholes QPP02, QPP05, QPP11, QPP14, QPP15, and QPP21 before and after the mining of Room Q are consistent with Peach's (1991) theory about the development of percolation networks. In the undisturbed condition, the pores were too poorly connected to provide enough flow for a pressure-buildup response. After Room $Q$ was mined and the halite had dilated to some degree, a better connected pore network was formed, allowing permeability and pore pressure to be estimated. Under these conditions, the measured pore pressure must reflect local stress conditions in the rock because no real connection to a "far-field" pore pressure exists. The orders-of-magnitude increase in permeability observed in the Small-Scale Mine-By experiment 
around the $96.5-\mathrm{cm}$ hole is also consistent with dilation increasing the connectivity of the pore network.

No measurable permeability or pore pressure was observed during the testing of map unit 9 in borehole C2H03 (Beauheim et al., 1991) and of PH-4 in the guard zone of SCP01 (Beauheim et al., 1993). Both of these units are relatively pure halite. The tested intervals in $\mathrm{C} 2 \mathrm{HO}$ Ond SCP01 were 7.8 to $9.1 \mathrm{~m}$ (2.0 to 2.3 room radii) and 8.8 to $9.9 \mathrm{~m}$ (2.0 to 2.3 room radii), respectively, from the nearest excavations. Insufficient dilation may have occurred at these locations to create an interconnected pore network above the percolation threshold.

Further evidence for the lack of interconnection among all halite porosity comes from geochemical observations. Krumhansl et al. (1991) discussed different brine chemistries associated with closely spaced $(<1 \mathrm{~m})$ weeps in the ribs of WIPP excavations. If the pores containing the brines were interconnected for a few million years, the chemistries would have equilibrated through diffusion. Consistent differences are also noted between the chemistries of brines from MB139, MB140, and map unit 0 (Roberts et al., 1999) that suggest that those units are not vertically interconnected. However, these conclusions about lack of connectivity in halite are based on average compositions. At the individual sample level, some percentage could be connected. Perhaps a percolation network exists that is somewhere below saturation, so some points in it are isolated. We do not know if the percolation network is also subcritical (below the percolation threshold). Nor do we know if this differs between/within layers and locations. 
Peach (1991) also noted that the creation/enhancement of permeability during dilation could be simultaneously counteracted by the healing of fractures in halite. This implies that permeability is a dynamic property that cannot be measured at one time and then assumed to remain constant. The anomalous-appearing changes in pore pressure observed in boreholes QPP02, QPP04, and QPP14 after the mining of Room Q may reflect ongoing changes to the pore network.

\subsection{Summary}

The porosity of the rocks around the WIPP excavations appears to have increased, in some places significantly, due to dilation and fracturing at a variety of scales. Pore pressures have decreased in response to dilation, fracturing, and flow to the repository, resulting in partially saturated and/or two-phase conditions in some locations. Permeability has increased in some locations due to dilation, microfracturing, and shear and extensional fracturing, but decreased in other locations because of vertical stress concentration. Hence, the repository is surrounded by a partially brine-saturated zone with increased porosity and permeability which grades outward into a zone at full saturation with altered permeability and high hydraulic gradients, although the pressure is lower than in the far field. This zone of altered permeability may grade into a region where only pore pressure has been altered (lowered) from far-field conditions, which in turn grades outward into the undisturbed far-field formation. The extent and properties of these zones are continuing to change as the stress field around the repository evolves.

On the time scale of the operational period of WIPP (decades), the far field lacks the capacity to fill all of the newly created porosity in and around the repository, much less pressurize it to near lithostatic pressure. After WIPP is closed, far-field flow toward the repository will continue, but 
the overall "healing" of the formation around the repository (closure) and compaction of the crushed-salt backfill will act to reduce both the hydraulic gradient and the porosity present near the waste. Thus, the amount of brine that ever comes into contact with waste will be controlled by the relative rates at which brine flow and repository closure occur.

\section{Implications for Modeling}

The existence/occurrence of excavation-induced permeability and pressure changes, pressuredependent permeability, and nonradial flow dimensions in the Salado has implications with regard to modeling of flow and transport. If hydraulic properties are dependent on current and past stress states, permeability values derived from tests conducted at locations under particular stress regimes cannot be assigned throughout a modeling domain with a variable stress regime. A rigorous model should include a coupling between hydraulic properties and the stress field, with a full recognition of the time-dependence of conditions and properties.

Finite-difference and finite-element models constructed with homogeneous layers have implicit flow dimensions of 2 if the permeable layers are completely confined or some value between 2 and 3 if different layers have different properties or properties are anisotropic. Incorporating heterogeneity in permeability within layers can alter the flow dimension. We now recognize that no inferred value of permeability can be separated from its associated flow dimension. If a permeability estimated assuming a subradial flow dimension is used as input to a homogeneous flow model, flow will be overestimated. Flow may, likewise, be underestimated if a permeability estimated assuming a greater-than-radial flow dimension is used in a model having an implicit dimension of 2 . 
Each of the layers of the Salado represented in the modeling for the WIPP Compliance Certification Application (US DOE, 1996) was treated as homogeneous. As a result, the CCA modeling calculated a larger brine flux toward and away from the WIPP repository than would have been calculated had conditions giving the subradial flow dimensions observed in most of the tests been implemented. However, the same CCA modeling would, for a given flux, underestimate the distance to which brine would flow away from the repository because it would assume that the brine was spread evenly through the entire volume of rock instead of being channeled within some smaller percentage of the volume. Based on the test results presented in Roberts et al. (1999), the Salado might better be modeled as a heterogeneous medium with nonradial flow dimensions.

All of the Salado permeability tests were conducted under conditions of induced high hydraulic gradients. Success in applying a Darcy-flow model to the interpretation of these tests does not necessarily imply that the model would provide a valid description of flow through the Salado under natural low-gradient conditions, as discussed by Beauheim et al. (1993). The available data suggest that a Darcy-flow model should adequately describe flow in the near-field around the WIPP repository so long as gradients are high, but flow may be overestimated after the repository pressurizes and gradients decrease.

\section{Conclusions}

Our conceptual model for far-field Salado hydrology involves permeability in anhydrite layers and at least some impure halite layers. Pure halite layers and some impure halite layers may not 
possess an interconnected pore network adequate to provide permeability. Pore pressures are probably very close to lithostatic pressure. In the near field (DRZ) around an excavation, dilation, creep, and shear have created and/or enhanced permeability and decreased pore pressure. Very close $(<1 \mathrm{~m}$ ?) to the excavations, these changes have resulted in partially saturated conditions. Whether flow occurs in the far field under natural gradients or only after some threshold gradient is reached is unknown. If far-field flow does occur, mean pore velocities are probably on the order of a meter per hundreds of thousands to tens of millions of years.

Pressure-pulse, constant-pressure flow, and pressure-recovery tests have been performed in anhydrite and halite intervals to evaluate the hydraulic properties controlling brine flow through the Salado. Permeabilities ranging from approximately $2 \times 10^{-23}$ to $3 \times 10^{-16} \mathrm{~m}^{2}$ have been interpreted from tests conducted on 30 stratigraphic intervals within $23 \mathrm{~m}$ of the WIPP underground excavations. Typical average permeability values for anhydrite range from approximately $10^{-20}$ to $10^{-18} \mathrm{~m}^{2}$, while those of halite are less than $10^{-20} \mathrm{~m}^{2}$. In the far field, halite permeabilities are probably less than $10^{-21} \mathrm{~m}^{2}$, except possibly in highly argillaceous halites. Pore pressures in 66 stratigraphic intervals range from atmospheric to $14.8 \mathrm{MPa}$.

Permeabilities of some tested intervals have been found to be dependent on the pressures at which the tests were conducted, which is interpreted as the result of fracture apertures changing in response to changes in effective stress. Flow dimensions inferred from most test responses are subradial, which is believed to reflect channeling of flow through fracture networks, or portions of fractures, that occupy a diminishing proportion of the radially available space, or through 
percolation networks that are not "saturated" (fully interconnected). This is probably related to the directional nature of the permeability created or enhanced by excavation effects. Other test responses indicate flow dimensions between radial and spherical, which may reflect propagation of pressure transients above or below the plane of the test interval or into regions of increased permeability (e.g., closer to an excavation). The variable stress and pore-pressure fields around the WIPP excavations probably contribute to the observed nonradial flow dimensions.

Inferred values of permeability cannot be separated from their associated flow dimensions. Therefore, numerical models of flow and transport should include heterogeneity that is structured to provide the same flow dimensions as are observed in hydraulic tests. Modeling of the Salado Formation around the WIPP repository should also include coupling between hydraulic properties and the evolving stress field because hydraulic properties change as the stress field changes.

Sandia is a multiprogram laboratory operated by Sandia Corporation, a Lockheed Martin Company, for the United States Department of Energy under contract DE-AC04-94AL85000.

\section{References}

Argüello, J.G., 1990. Pretest 3-D Finite Element Analysis of the WIPP Intermediate-Scale Borehole Test, SAND90-2055, Sandia National Laboratories, Albuquerque, NM.

Barker, J.A., 1988. A generalized radial-flow model for pumping tests in fractured rock. Water Resources Res. 24 (10), 1796-1804.

Beauheim, R.L., Saulnier, G.J., Jr., Avis, J.D., 1991. Interpretation of Brine-Permeability Tests of the Salado Formation at the Waste Isolation Pilot Plant Site: First Interim Report, SAND90-0083, Sandia National Laboratories, Albuquerque, NM.

Beauheim, R.L., Roberts, R.M., Dale, T.F., Fort, M.D., Stensrud, W.A., 1993. Hydraulic Testing of Salado Formation Evaporites at the Waste Isolation Pilot Plant Site: Second Interpretive Report, SAND92-0533, Sandia National Laboratories, Albuquerque, NM. 
Black, J.H., Barker, J.A., Noy, D.J., 1986. Crosshole Investigations - The Method, Theory and Analysis of Crosshole Sinusoidal Pressure Tests in Fissured Rock, Stripa Project IR 86-03, SKB, Stockholm, Sweden.

Borns, D.J., 1985. Marker Bed 139: A Study of Drillcore From a Systematic Array, SAND85-0023, Sandia National Laboratories, Albuquerque, NM.

Borns, D.J., Stormont, J.C., 1988. An Interim Report on Excavation Effect Studies at the Waste Isolation Pilot Plant: The Delineation of the Disturbed Rock Zone, SAND87-1375, Sandia National Laboratories, Albuquerque, NM.

Borns, D.J., Stormont, J.C., 1989. The delineation of the disturbed rock zone surrounding excavations in salt, Rock Mechanics as a Guide for Efficient Utilization of Natural Resources, Proceedings of the 30th U.S. Symposium, West Virginia University, Morgantown, WV, June 1922, 1989. Ed. A.W. Khair. Brookfield, VT: A.A. Balkema. 353-360.

Deal, D.E., Abitz, R.J., Belski, D.S., Case, J.B., Crawley, M.E., Deshler, R.M., Drez, P.E., Givens, C.A., King, R.B., Lauctes, B.A., Myers, J., Niou, S., Pietz, J.M., Roggenthen, W.M., Tyburski, J.R., Wallace, M.G., 1989. Brine Sampling and Evaluation Program 1988 Report, DOE/WIPP 89-015, US DOE Waste Isolation Pilot Plant Project Office, Carlsbad, NM.

Doe, T.W., 1991. Fractional dimension analysis of constant-pressure well tests, Proceedings: 1991 SPE Annual Technical Conference and Exhibition, Dallas, TX, October 6-9, 1991. Richardson, TX: Society of Petroleum Engineers. Formation Evaluation \& Reservoir Geology, 461-467.

Domski, P.S., Upton, D.T., Beauheim, R.L., 1996. Hydraulic Testing Around Room Q: Evaluation of the Effects of Mining on the Hydraulic Properties of Salado Evaporites, SAND96-0435, Sandia National Laboratories, Albuquerque, NM.

Krumhansl, J.L., Kimball, K.M., Stein, C.L., 1991. Intergranular Fluid Compositions from the Waste Isolation Pilot Plant (WIPP), Southeastern New Mexico, SAND90-0584, Sandia National Laboratories, Albuquerque, NM.

Mercer, J.W., 1987. Compilation of Hydrologic Data from Drilling the Salado and Castile Formations Near the Waste Isolation Pilot Plant (WIPP) Site in Southeastern New Mexico, SAND86-0954, Sandia National Laboratories, Albuquerque, NM.

Neuzil, C.E., 1986. Groundwater flow in low-permeability environments, Water Resources Res. 22 (8), 1163-1195.

Noy, D.J., Barker, J.A. Black, J.H., Holmes, D.C., 1988. Crosshole Investigations Implementation and Fractional Dimension Interpretation of Sinusoidal Tests, Stripa Project TR 88-01, SKB, Stockholm, Sweden. 
Pascal, H., 1981. Nonsteady flow through porous media in the presence of a threshold gradient, Acta Mechanica. 39, 207-224.

Peach, C.J., 1991. Influence of deformation on the fluid transport properties of salt rocks. Geologica Ultraiectina, no. 77, Instituut voor Aardwetenschappen der Rijksuniversiteit Utrecht, Utrecht, the Netherlands.

Pickens, J.F., Grisak, G.E., Avis, J.D., Belanger, D.W., Thury, M., 1987. Analysis and interpretation of borehole hydraulic tests in deep boreholes: Principles, model development, and applications, Water Resources Res. 23 (7), 1341-1375.

Powers, D.W., Hassinger, B.W., 1985. Synsedimentary dissolution pits in halite of the Permian Salado Formation, southeastern New Mexico, Journal of Sedimentary Petrology. 55 (5), 769-773.

Remson, I., Gorelick, S.M., 1982. Hydrologic issues in repository siting, The Technology of High-Level Nuclear Waste Disposal, Ed. P.L. Hofmann. DOE/TIC-4621. Washington, DC: US DOE. Vol. 2, 46-52.

Roberts, R.M., Beauheim, R.L., Domski, P.S., 1999. Hydraulic Testing of Salado Formation Evaporites at the Waste Isolation Pilot Plant Site: Final Report, SAND98-2537, Sandia National Laboratories, Albuquerque, NM.

Sandia National Laboratories and D'Appolonia Consulting Engineers, 1982. Basic Data Report for Drillhole WIPP 12 (Waste Isolation Pilot Plant-WIPP), SAND82-2336, Sandia National Laboratories, Albuquerque, NM.

Stormont, J.C., Howard, C.L., Daemen, J.J.K., 1991a. In Situ Measurements of Rock Salt Permeability Changes Due to Nearby Excavation, SAND90-3134, Sandia National Laboratories, Albuquerque, NM.

Stormont, J.C., Howard, C.L., Daemen, J.J.K., 1991. Changes in rock salt permeability due to nearby excavation, Rock Mechanics as a Multidisciplinary Science, Proceedings of the 32nd U.S. Symposium, The University of Oklahoma, Norman, Oklahoma, July 10-12, 1991. Ed. J-C. Roegiers. Brookfield, VT: A.A. Balkema. 899-907.

Swartzendruber, D., 1962. Non-Darcy flow behavior in liquid-saturated porous media, Journal of Geophysical Research. 67 (13), 5205-5213.

US Department of Energy, 1996. Title 40 CFR Part 191 Compliance Certification Application for the Waste Isolation Pilot Plant, DOE/CAO-1996-2184, US DOE Waste Isolation Pilot Plant, Carlsbad Area Office, Carlsbad, NM.

Wawersik, W.R., Stone, C.M., 1989. A characterization of pressure records in inelastic rock demonstrated by hydraulic fracturing measurements in salt, International Journal of Rock Mechanics and Mining Sciences \& Geomechanics Abstracts. 26 (6), 613-627. 
Wawersik, W.R., Carlson, L.W., Henfling, J.A., Borns, D.J., Beauheim, R.L., Howard, C.L., Roberts, R.M., 1997. Hydraulic Fracturing Tests in Anhydrite Interbeds in the WIPP, Marker Beds 139 and 140, SAND95-0596, Sandia National Laboratories, Albuquerque, NM.

Westinghouse Electric Corporation, 1989. Geotechnical Field Data and Analysis Report, July 1987-June 1988, Volume II, DOE/WIPP 89-009, US DOE, Carlsbad, NM. 